\title{
Climatic Impact of a Greenland Deglaciation and Its Possible Irreversibility
}

\author{
T. TONIAZZO \\ Hadley Centre for Climate Prediction and Research, Met Office, Bracknell, Berkshire, United Kingdom \\ J. M. GREGORY \\ Hadley Centre for Climate Prediction and Research, Met Office, Bracknell, Berkshire, and Centre for Global Atmospheric Modelling, \\ Department of Meteorology, University of Reading, Reading, United Kingdom

\section{P. HUYBRECHTS} \\ Alfred-Wegener-Institüt für Polar- und Meeresforschung, Bremerhaven, Germany, and Department Geografie, Vrije Universiteit Brussel, \\ Brussels, Belgium
}

(Manuscript received 30 December 2002, in final form 19 June 2003)

\section{ABSTRACT}

\begin{abstract}
Warmer climate conditions persisting for a period of many centuries could lead to the disappearance of the Greenland ice sheet, with a related 7-m rise in sea level. The question is addressed of whether the ice sheet could be regenerated if preindustrial climate conditions were reestablished after its melting. The HadCM 3 coupled atmosphere-ocean GCM is used to simulate the global and regional climate with preindustrial atmospheric greenhouse gas composition and with the Greenland ice sheet removed. Two separate cases are considered. In one, the surface topography of Greenland is given by that of the bedrock currently buried under the ice sheet. In the other, a readjustment to isostatic equilibrium of the unloaded orography is taken into account, giving higher elevations. In both cases, there is greater summer melting than in the current climate, leading to partially snow-free summers with much higher temperatures. On the long-term average, there is no accumulation of snow. The implication of this result is that the removal of the Greenland ice sheet due to a prolonged climatic warming would be irreversible.
\end{abstract}

\section{Introduction}

As greenhouse-gas-forced global warming progresses in the course of the present century, it is expected that the surface mass balance of the Greenland ice sheet will become negative [Ohmura et al. 1996; Thompson and Pollard 1997; Gregory and Lowe 2000; see also Church et al. 2001 in the IPCC Third Assessment Report (TAR)].

At present, the Greenland ice sheet maintains nearzero mass balance through surface melting and discharge of icebergs into the sea, in roughly equal shares (TAR, Table 11.5). Its high altitude (3200 $\mathrm{m}$ at the summit) and its cold surface ensure very cold local climatic conditions in central Greenland, and a permanent cold high pressure center that forces cyclone systems (and hence precipitation) to skirt along its sides with little penetration into the interior (see, e.g., Murphy et al. 2002). Seasonal melting is even more confined to the

Corresponding author address: J. M. Gregory, Hadley Centre, Met Office, London Rd., Bracknell, Berkshire RG12 2SY, United Kingdom.

E-mail: jonathan.gregory@metoffice.com margins of the ice sheet. Modeling studies (summarized by TAR, Table 11.7) all agree that under global warming Greenland will become warmer and wetter, but there is consensus that the increasing precipitation will not be sufficient to balance the increasing melting.

Palaeoclimatic studies confirm a large sensitivity of the Greenland regional climate to warm global conditions (Dahl-Jensen et al. 1993; Cuffey and Clow 1997; Cuffey and Marshall 2000). In an anthropogenic warming scenario, even after $\mathrm{CO}_{2}$ concentrations are stabilized, progressive melting of the ice sheet will continue. A climate more than about $3^{\circ} \mathrm{C}$ warmer over Greenland persisting for a period of a thousand years or longer could result in a complete destruction of the ice sheet (Huybrechts and De Wolde 1999; Greve 2000; TAR). A direct consequence of this would be a global-average sea level rise of about $7 \mathrm{~m}$.

Here we investigate the extreme scenario in which the ice sheet has disappeared completely. The main question we ask is whether an ice sheet would tend to reform on Greenland if the climate were returned to the present-day climate. To this end, we perturb a simulated present-day climate by removing the Greenland ice sheet. 


\section{Experimental design}

Because the departures of local radiative and orographic forcing with respect to control conditions are large on Greenland, an adequate treatment of the icefree Greenland (IFG) problem requires the use of a full numerical general circulation model (GCM). We use the Hadley Centre coupled atmosphere-ocean GCM (HadCM3) with a modified orography and land-surfacetype initialization over Greenland. A "control" run with preindustrial greenhouse gas concentrations is available for this model, giving a reference quasi-steady-state climate over many centuries, which we take as representative of the present-day climate (against which it was assessed: Gordon et al. 2000). A similar study has been done in a palaeoclimatic context by Crowley and Baum (1995), indicating net accumulation of ice over ice-free Greenland to be unlikely. That work used a GCM with prescribed present-day sea surface temperature and sea ice conditions, thus largely suppressing changes that could occur in the Atlantic and Arctic as a result of the removal of the ice sheet, which could also influence the climate of Greenland. A coupled model can simulate such effects.

The atmospheric component of HadCM3 (HadAM3: Pope et al. 2000) has a resolution of $2.5^{\circ}$ latitude $\times$ $3.75^{\circ}$ longitude. (Crowley and Baum used $4.5^{\circ} \times 7.5^{\circ}$.) Over Greenland, the performance of HadAM3, forced with climatological SSTs, has been assessed against observations and against the European Centre for MediumRange Weather Forecasts (ECMWF) Re-Analysis (ERA: Gibson et al. 1996) in Murphy et al. (2001). They indicate generally good agreement with precipitation, temperature, and wind data except for a warm summer bias (related to excessive shortwave heating at the surface), a weak cold winter bias (excessive longwave cooling), and a wet bias in the south (inefficient orographic blocking).

In a coupled mode, the HadCM3 performance suffers from similar errors. The simulated mass balance of the Greenland ice sheet (Gregory and Lowe 2000) is affected by excessive model precipitation over Greenland, almost entirely snowfall and about 50\% larger than the observed accumulation. Part of this wet bias is related to the resolution of the GCM being insufficient to represent the steep margins of the ice sheet. Relatively low coastal topography, especially in the south, allows advection of moist air farther into the interior of Greenland and thus more snowfall, as noted for HadAM3. On the other hand, although surface melting is also sensitive to topography, the simulated ablation is close to observationally based estimates. Difficulties relating to inadequate resolution of the ice sheet margins obviously cannot arise in the IFG simulations, but there may be analogous problems in mountainous areas, as discussed later. If there is also a wet bias in the IFG simulations, it would encourage reglaciation.

Since ice sheet flow and iceberg calving are not sim- ulated by the GCM, snow steadily accumulates on ice sheet points in the control. The effect of this accumulation on the control climate is negligible as the surface elevation is artificially kept constant and a small compensating freshwater flux correction is applied to the ocean.

We started the IFG integrations from a point in the middle of the control run, having replaced the ice sheet orography with that appropriate for the bedrock underlying the current ice sheet. Two models were run with two different assumptions. In the first, which we will refer to as the "PDBR" case, we take the observed present-day bedrock topography, characterized by two main mountain ranges on the southern tip and on the east coast, a wide low central plain (with parts below sea level), and minor elevations in the west and in the north. In the second model, the topography is taken to be lifted by isostatic rebound of the earth's crust once the load of the ice sheet is removed. This case, which we will refer to as "ULBR" ("unloaded bedrock"), shows slightly higher summit elevations than the PDBR case and a central plateau at around 500-m altitude. Complete isostatic adjustment of the unloaded bedrock would occur over a period of about 20000 years, much of it in the first 10000 years (Letréguilly et al. 1991). Maps of the topographic height for the present-day ice sheet (control) and the two modified runs (PDBR and ULBR) are shown in Fig. 1. Also shown on these maps are four different regions that, due to their different elevation and their different geographical location, tend to have different climatic properties. Going anticlockwise from the north, we will refer to these regions as North, West and Central, South, and East. The subdivision is nonstandard for Greenland (see, e.g., Murphy et al. 2001) because the modified topographies are very different from that of the control. Note that at the horizontal resolution of the atmospheric grid, the coastal mountain ranges are represented with a reduced altitude, as illustrated by Fig. 2. This is particularly marked for the southern mountain range of Greenland, for all three cases shown in Fig. 1.

The surface characteristics over Greenland for the modified models were taken to reflect bare soil with average texture and albedo, like that found in nearby northeastern Canada. No vegetation or other modifications of the surface were considered. The land-sea mask was left unmodified because a sea level rise of $7 \mathrm{~m}$ would make no difference to the land area at the resolution of the GCM. Part of the interior of Greenland in the PDBR case lies below sea level. The possibility of a partial water cover of the lower-lying areas, with a lower surface albedo during summer, implies that the warming of the ice-free land could be enhanced as compared to our model results. Our omission of this effect therefore tends to favor ice sheet regrowth.

The two IFG models were run for several decades (six for the PDBR case, four for the ULBR case) until it was judged that a steady state was approximately 

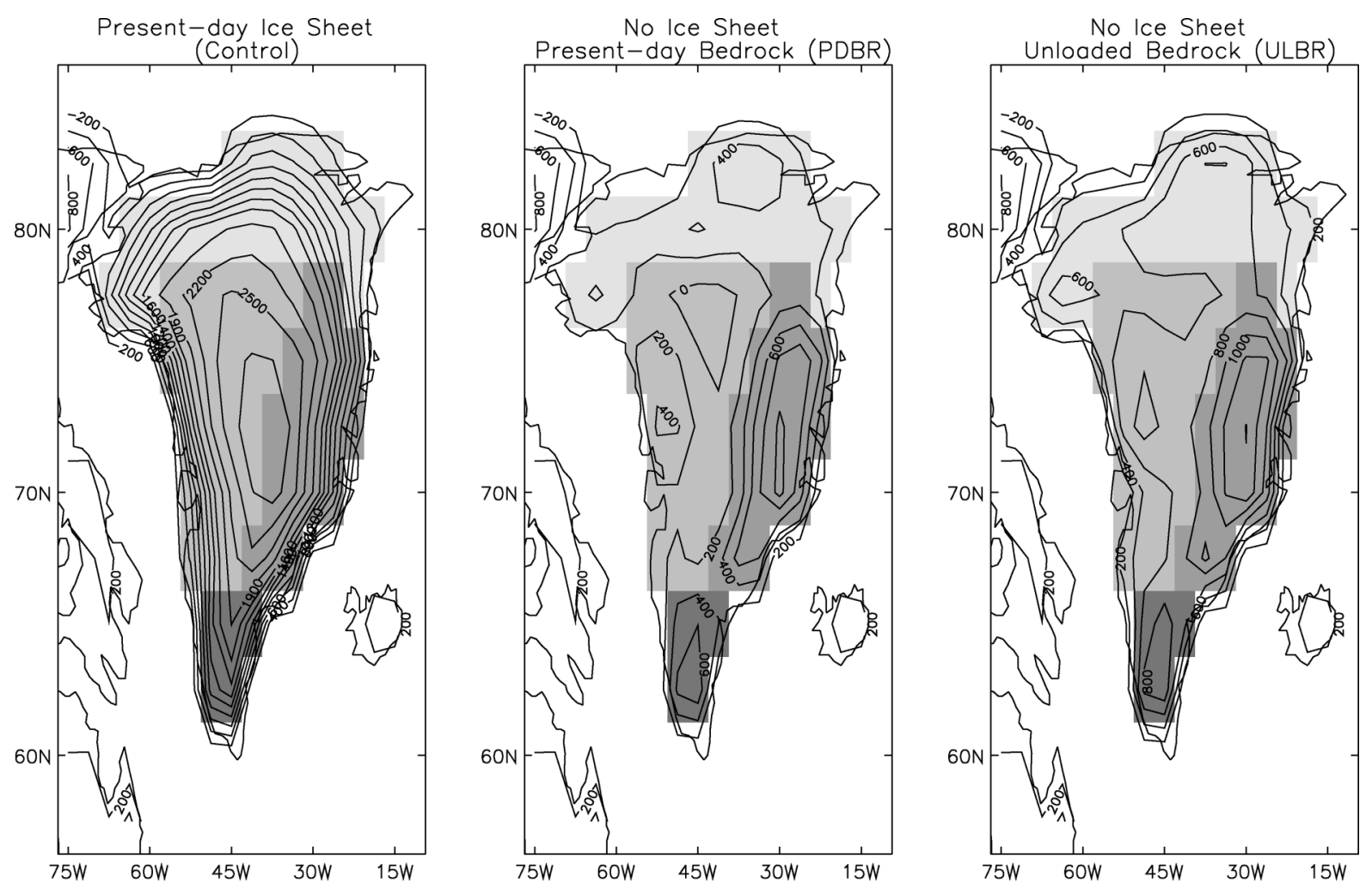

FIG. 1. Greenland orographic height for the control climate model, and for the two no-ice-sheet models. Contour levels are drawn at -100 , $0,200,400,600,800,1000,1200,1400,1600,1900,2200,2500,2800$, and $3100 \mathrm{~m}$ above sea level. Shaded areas mark the four regions referred to as North, West and Central, South, and East.

attained. Unless otherwise specified, climate-mean data presented hereafter refer to the last two decades of each run, and the corresponding control means.

\section{Snow amount and snow cover}

Figure 3 shows time series of annual average snow cover (millimeters water equivalent, or kilograms per square meter) in the four regions defined above for the two no-ice-sheet runs. Snow cover increases year-onyear if there is net accumulation, and the final value in each time series is the amount of snow that has built up during the period of the experiment. The absence of any clear trend in the amount of snow lying on the ground shows that net accumulation of ice is not taking place over the simulated period over Greenland. This is the case except for the south in the ULBR case, where accumulation takes place on a single model land grid box on the coast that has the highest local elevation. In view of the difficulty in accurately simulating precipitation on such a location, and of the known bias of the control which produces a large excess of precipitation in this region due to inefficient orographic blocking, this result is not conclusive evidence of accumulation. Similar arguments hold for two eastern coastal grid points that have very large fluctuation in snow amount in the ULBR case. When the data from such grid points are excluded (thin dot-dash curves in Fig. 3), the snow amount is the same in the two no-ice-sheet runs at a modest, stable level.

The snow cover mainly reflects local altitude in the two modified models, indicating a high sensitivity to orographic forcing. The surface temperature lapse rate (not shown) and the precipitation rates increasing with altitude indicate the prevalence of moist conditions especially on the eastern and southern mountain ranges.

The snow cover has significant seasonal variations (Fig. 4). In summer, a substantial fraction of central Greenland is snow free or nearly snow free. Summer snow cover is smaller in the PDBR case due to its lower altitude. Even in those places where there usually remains some snow cover at the end of the summer, the absence of long-term accumulation indicates that there must be occasional years in which the snow melts completely. That is, the potential for melting exceeds the snowfall on average.

\section{Water and heat fluxes}

The annual cycle of surface water fluxes is shown in Fig. 5. The most obvious feature is that the two IFG cases are much more similar to each other than to the control. Annual-average precipitation rates in the noice-sheet runs are comparable with the control in the 

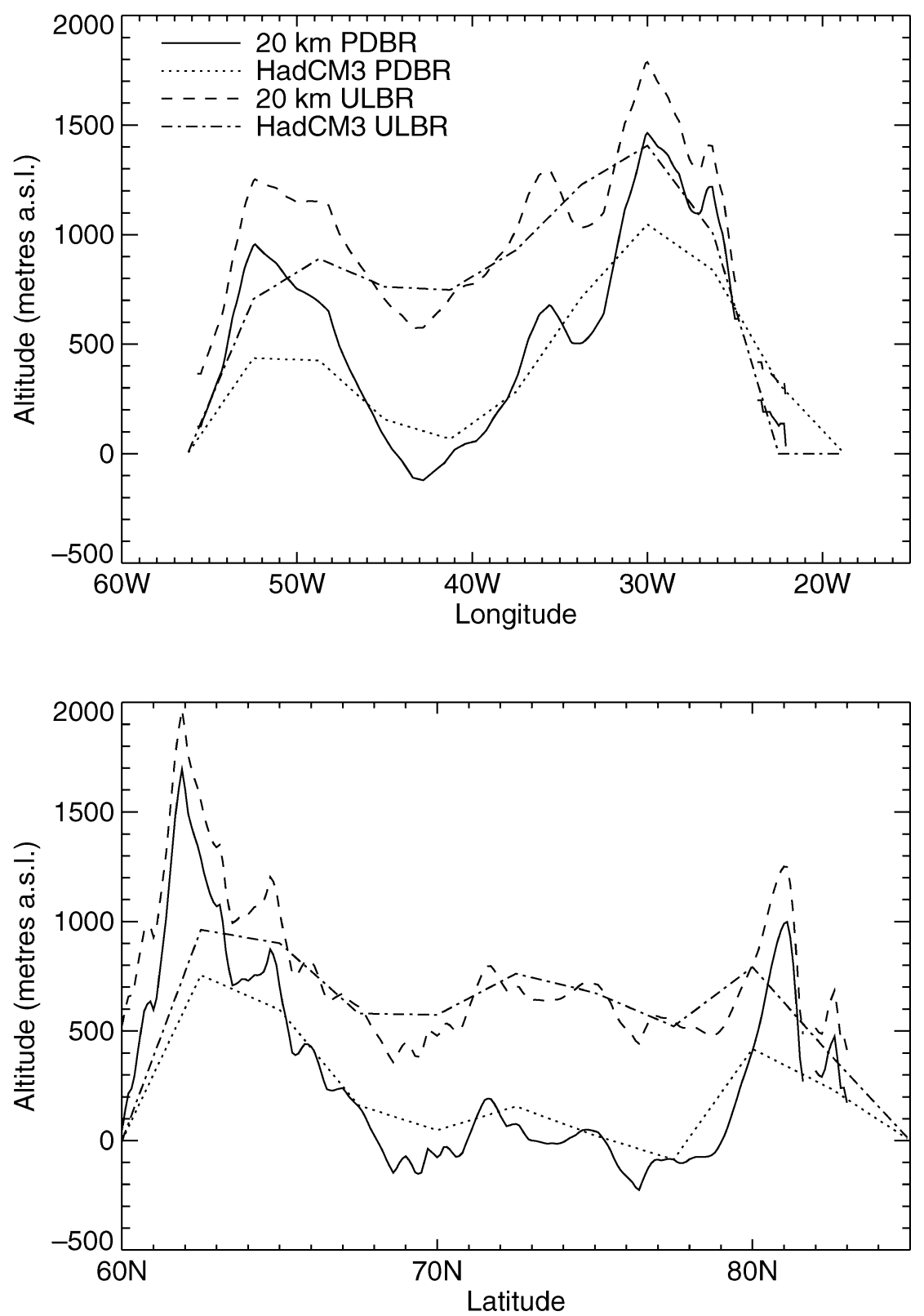

FIG. 2. Transects of Greenland bedrock topography at 20-km resolution and as used at HadCM3 resolution in the no-ice-sheet models: (top) an east-west transect at $72.5^{\circ} \mathrm{N}$ and (bottom) a southnorth transect at $45^{\circ} \mathrm{W}$ passing through the southern tip of Greenland.

Western and Central region, and somewhat higher in the East and in the North. The Greenland average is increased by $17 \%$. From autumn to spring, precipitation is nearly all solid in all cases. In summer in the IFG cases, consistent with their higher surface temperature (shown later), solid precipitation is reduced and rainfall increased; rainfall accounts for more than a fourth of the total annual precipitation. Still, total annual snowfall is slightly larger in the modified climates when the southernmost mountain range is excluded (21 and 36 $\mathrm{mm} \mathrm{yr}^{-1}$ more than control for the PDBR and ULBR cases, respectively).

The dominant difference between the IFG cases and the control is the more vigorous melting season, which returns the mass balance to zero, even where accumulation during the rest of the year has been greater. Greater snowmelt produces increased runoff and evaporation. The latter partly drains from a much increased summer soil moisture content that builds up early in summer. It is likely that some of the increased rainfall in early 

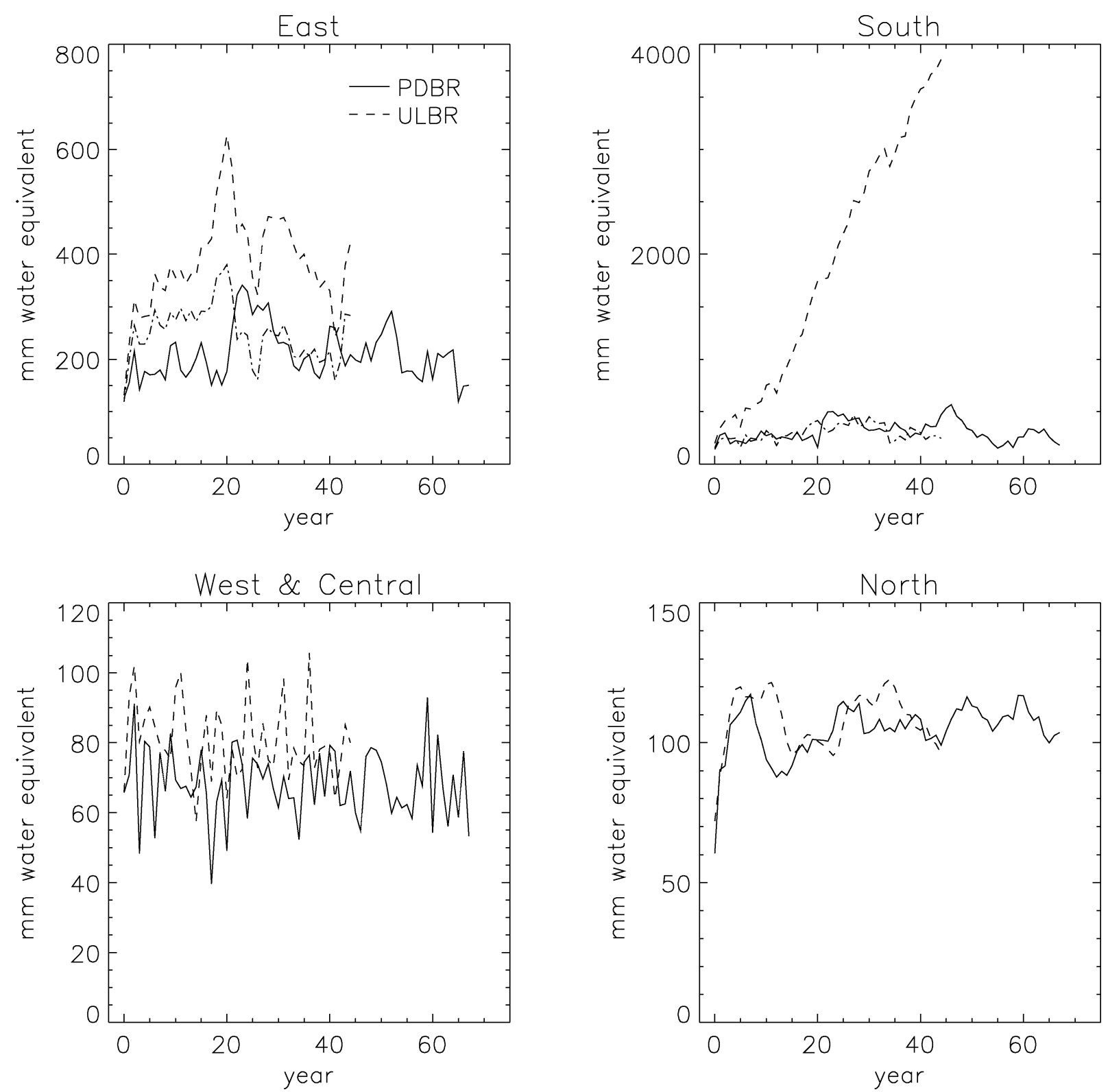

FIG. 3. Cumulative mass balance $\left(\mathrm{kg} \mathrm{m}^{-2}\right)$ over North, East, South, and Central and West Greenland. The solid line refers to the PDBR case, the dashed line to the ULBR case. The dot-dash lines show the ULBR case with the exclusion of exceptional points, as discussed in the text. The absence of a trend indicates no tendency to accumulate. (The values plotted are annual averages of the snow cover, which rises year-on-year if there is net accumulation.)

summer is due to increased evaporation. In the control, evaporation is negligible but there is significant sublimation of snow. Deposition (negative sublimation) is greater in the IFG runs, indicating more atmospheric moisture in the near-surface layer on Greenland.

The annual cycle of surface heat fluxes is shown in Fig. 6. As with the water fluxes, the two no-ice-sheet cases behave essentially identically. Winter conditions at the surface are regulated by an approximate balance between heating by the atmosphere across the near-surface inversion layer and cooling from longwave (LW) emission. Compared to the control climate, the additional atmospheric layers above the lower surface in the IFG models are warmer, thus reducing net surface LW losses. The surface layer is warmer, resulting in a weaker inversion, and hence also reduced turbulent heat fluxes. Snowfall accounts for a small, negative latent heat flux with little variation between the models.

The most striking difference between the no-ice-sheet runs and the control climate (Fig. 6, second left-hand panel from the top) is the increase in net downward surface shortwave (SW) flux, which follows early thaw- 

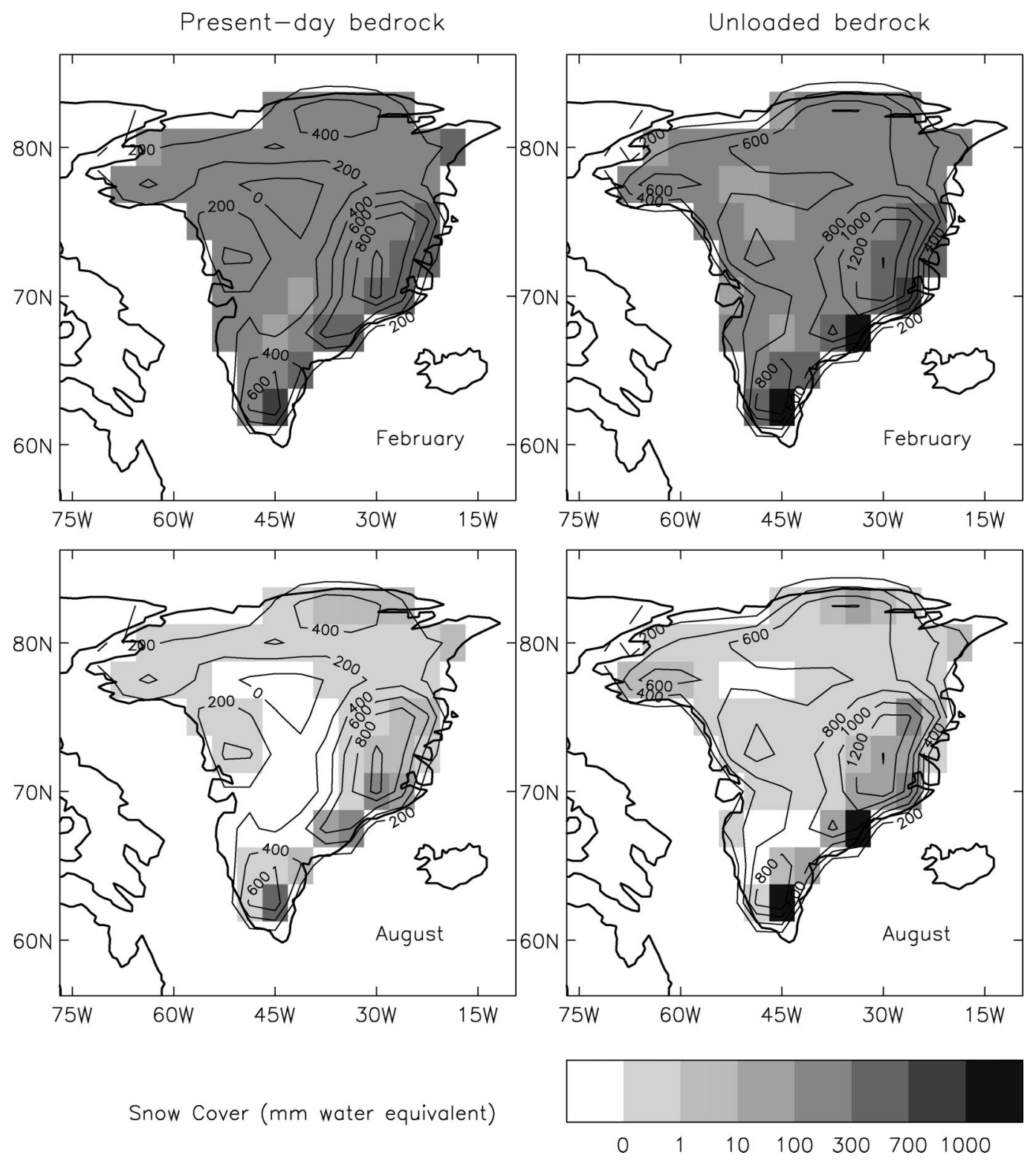

FIG. 4. Average Feb and Aug snow cover over Greenland for the IFG runs. The averages are calculated over all days, including days when no snow cover remains: (left) the PDBR case and (right) the ULBR case. Most of Greenland in winter has a snow cover between 100 and $300 \mathrm{~mm}$. Overplotted are levels of constant orographic height in meters at intervals of $200 \mathrm{~m}$.

ing in May, in turn caused by the reduced winter LW loss. Once the snow has melted in some areas, laying bare some darker soil, a positive feedback loop via surface albedo between melting and surface SW absorption is started, a phenomenon which does not occur in the permanently ice-covered Greenland of the control climate. Cloud radiative forcing at the surface (i.e., the difference in surface radiative flux caused by the presence of clouds, all else being equal) is significantly different from the control climate only in the melting season (not shown), although cloud cover is slightly increased in the IFG cases. In the latter part of the melting season, the increased SW heating is also partially offset by greater latent and sensible heat loss compared to the control climate.

\section{Climate and atmospheric circulation over Greenland}

The annual-mean average Greenland surface air temperature in the no-ice-sheet climates is $7.7^{\circ}$ and $6.7^{\circ} \mathrm{C}$ (for the PDBR and ULBR cases, respectively) higher than in the control climate, which has $-22.3^{\circ} \mathrm{C}$. The difference is largest, about twice as much, in summer, 


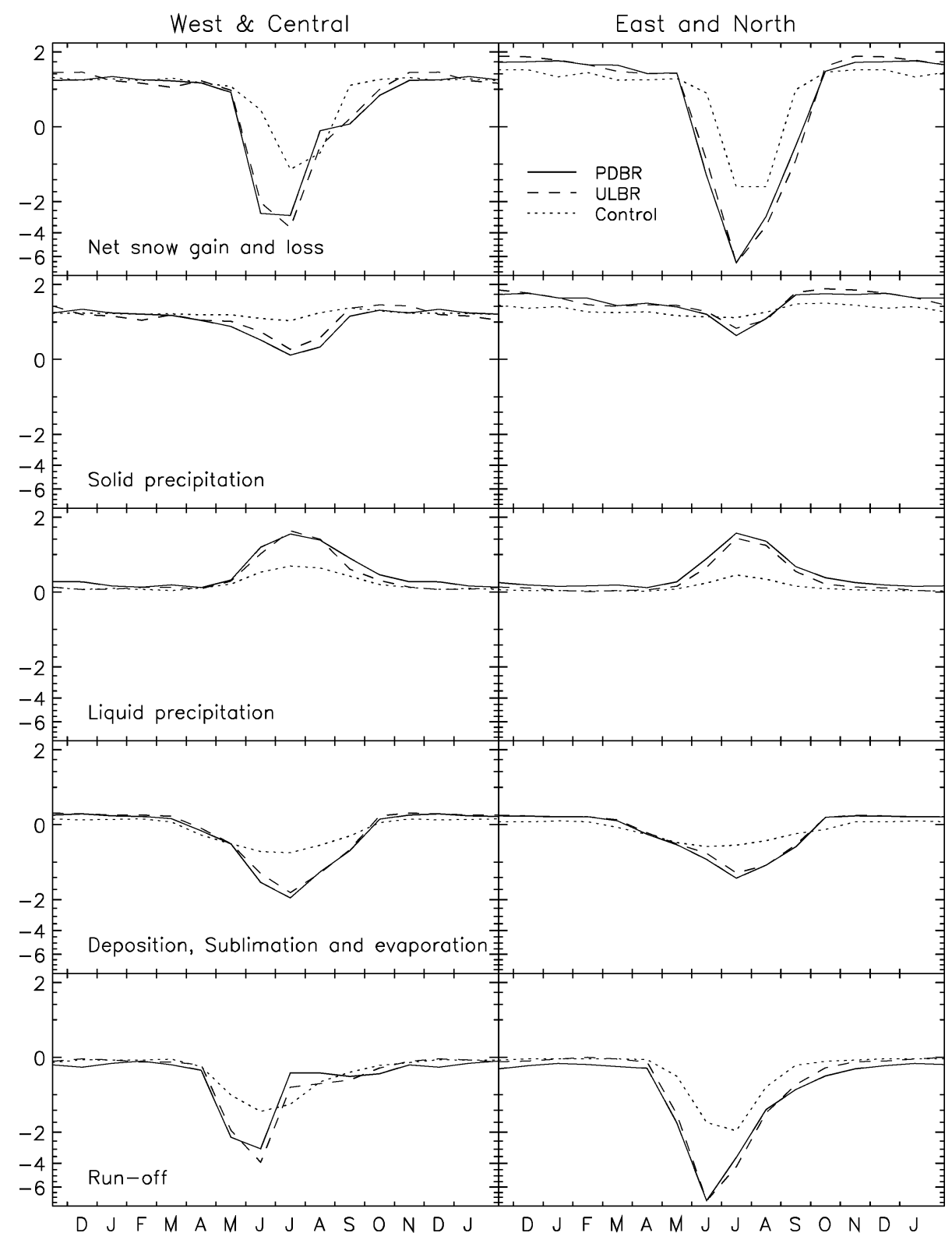

FIG. 5. Annual hydrological cycle: (left) the Central and West region, (right) the average of the North and East regions, as defined in Fig. 1. All quantities are in millimeters per day water equivalent. Fluxes toward the surface are counted as positive. (The southern region is excluded because of its large variability.)

and more pronounced in central Greenland, where it reaches up to $29^{\circ} \mathrm{C}$ for the July mean. July and August average temperatures in the central region are $13^{\circ}$ and $7^{\circ} \mathrm{C}$, respectively, for the PDBR case, and $10^{\circ}$ and $5^{\circ} \mathrm{C}$ for the ULBR. These results are similar to those of Crowley and Baum (1995), who found $10^{\circ} \mathrm{C}$ for JuneAugust (JJA) assuming flat land at sea level, and $8^{\circ} \mathrm{C}$ with a rough representation of rebounded topography. Such monthly average summer temperatures are comparable to those in forest areas in Alaska or Scandinavia. If a boreal forest could develop on Greenland, it would reduce the surface albedo significantly, resulting in even higher summer temperatures, as found by Crowley and Baum. Winter conditions are still cold on the deglaciated Greenland at less than $-27^{\circ} \mathrm{C}$ on average in February, not dissimilar from eastern Siberia.

Higher winter and spring atmospheric temperatures in the no-ice-sheet climates are responsible for earlier thawing (previous section). The warmer state of the atmosphere in these seasons is principally attributable to the different land altitude and temperature, and the related differences in the circulation, rather than to dif- 


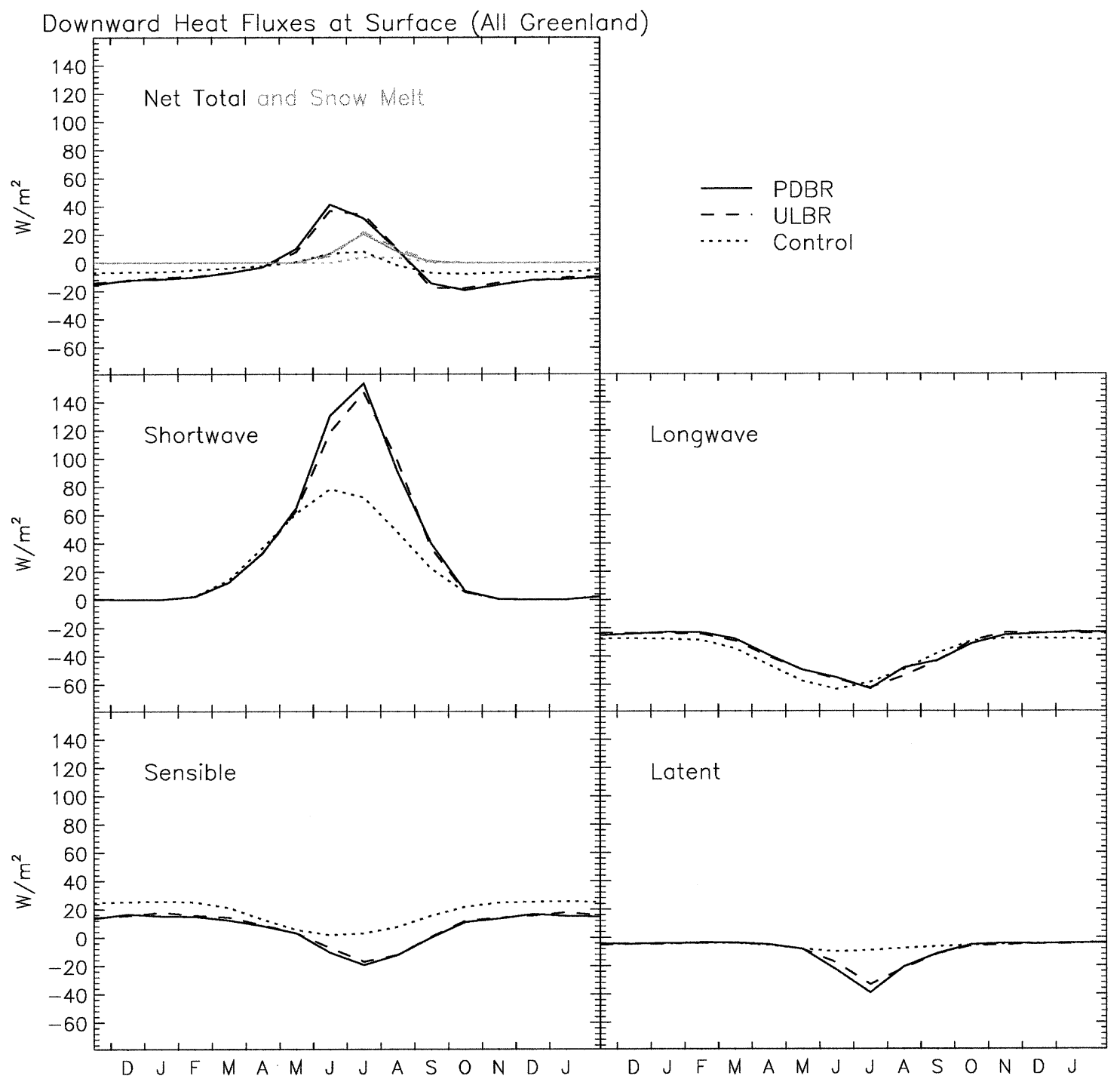

FIG. 6. Annual cycle of surface heat fluxes, averaged over all of Greenland. The sign convention is positive into the surface. The continuous line refers to the PDBR case, the broken line to the ULBR case, and the dotted one to the control. The heat fluxes absorbed by snow melt are shown in the top panel with lighter lines.

ferences in local thermal forcing. The differences in circulations also reflect a known sensitivity of the atmospheric model (Murphy et al. 2001) to orographic forcing in this geographical area.

Figure 7 details these considerations. Due to the lower orography, Greenland presents a reduced barrier to flow. In winter in the HadCM3 control, Greenland is covered by a cold anticyclone, with a much increased tendency, compared to observations, of the surface winds to maintain a katabatic flow off the ice sheet (Murphy et al. 2001). In the no-ice-sheet model, the Iceland low shifts and deepens somewhat and the associated cyclonic circulation extends over Greenland. Having the larger orography change, the PDBR case shows slightly greater differences; in the remaining figures, we show only this case since the two no-ice-sheet cases are very similar.
The reduced blocking along the southeastern coast of Greenland is attributable to lower Froude numbers, which depend also on the warmer surface in addition to the lower altitude. The steady-state climate is achieved when reduced blocking due to lower orography allows for some surface warming, which in turn further encourages cross-orographic circulation.

The differences in low-level winter circulation are directly reflected in the differences in precipitation described earlier (section 4). In the present climate, precipitation on Greenland is dominated by onshore flow from the Iceland low striking the southeast, with smaller contributions on the west coast (Ohmura and Reeh 1991). Without the ice sheet, increases in precipitation, correlated with the greater incursion of winds from the Atlantic, are found in the East and the North, and in a 


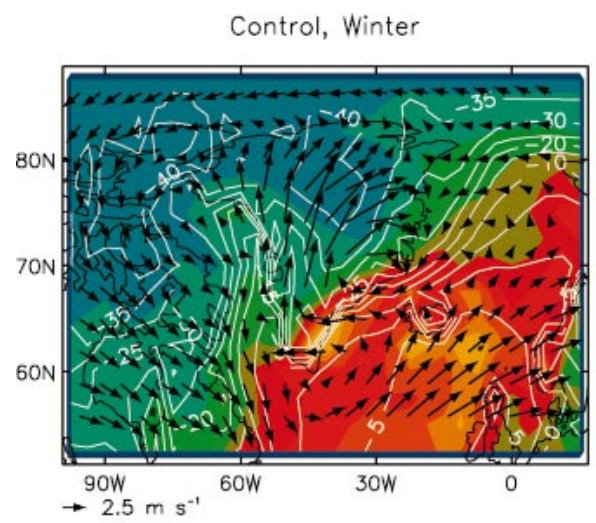

No ice sheet, PDBR, Winter

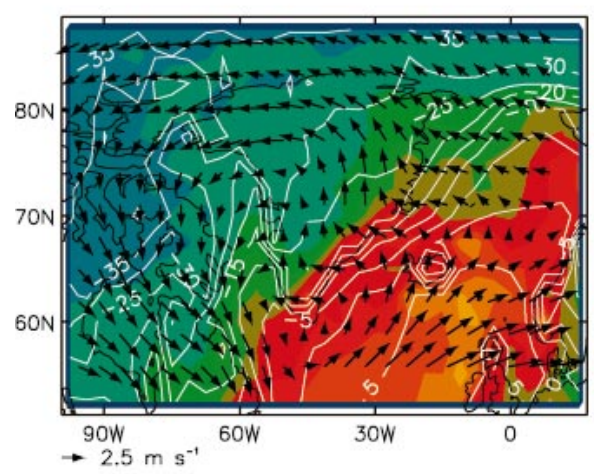

Control, Summer

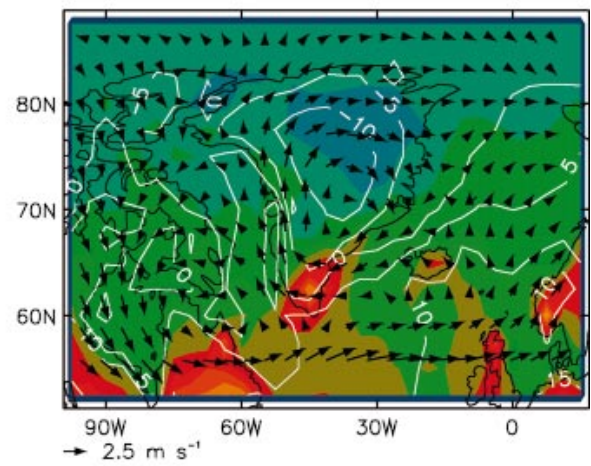

No ice sheet, PDBR, Summer

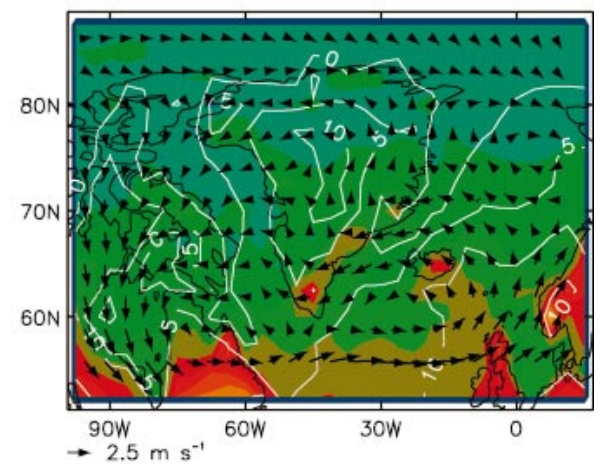

$\begin{array}{lllll}0 & 1 & 2 & 3 & 4\end{array}$

Difference, Winter

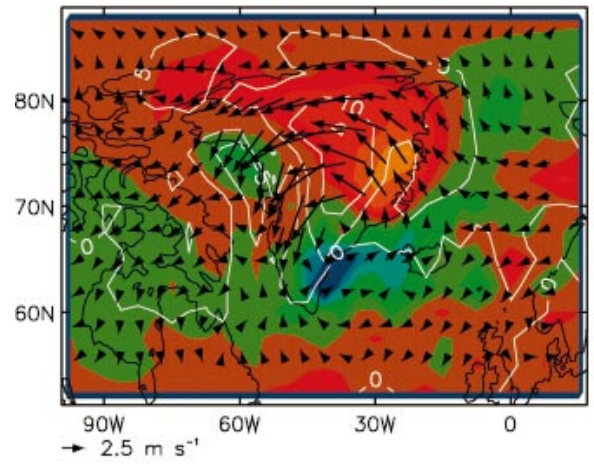

Difference, Summer

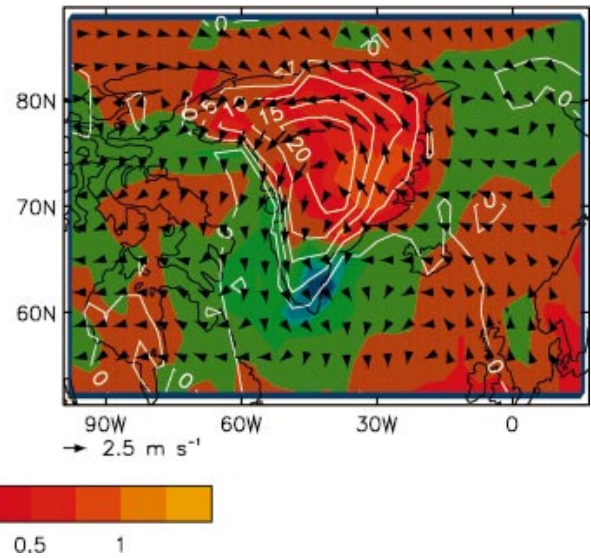

FIG. 7. Winds at model level 5 ( $\sigma=0.87$ i.e., approximately $870 \mathrm{hPa}$ over a surface at sea level) (arrows); 1.5-m air temperature (contour lines, in ${ }^{\circ} \mathrm{C}$ ); and total precipitation rate (color coding, in $\mathrm{mm} \mathrm{day}^{-1}$ ), for winter (DJF) and summer (JJA) in the control, the PDBR no-ice-sheet run, and their difference. The ULBR run is very similar to the PDBR.

"plume" extending across to the northwest. There is a reduction in the West because the flow now sweeping across the island resists onshore winds from Baffin Bay and a stronger one in the South since the flow now tends farther northeast before turning inland.

The precipitation on the coastal range of southern
Greenland is mainly orographically generated, and the resolution of HadAM3 is not sufficient to deliver a good performance there (Murphy et al. 2001). However, this is the most likely site for inception of a new ice cap, given that in all the runs snowfall is by far the greatest in the south. The issue of whether, in the absence of the 
ice sheet, accumulation would take place in the South region should be addressed by using a model with increased resolution.

The warmer temperatures in central Greenland are mainly dependent on the incomplete blocking in the east and on the low altitude of the plateau. In summer (Fig. 7), we find similar patterns to those of winter, but thermal forcing due to increased surface SW following snowmelt now dominates the changes in circulation and surface temperatures. The inversion layer is removed, and abundant soil moisture is added to the atmosphere. This encourages air ascent and low-level cyclonic flow, allowing an easier penetration of North Atlantic air masses into the interior of the island.

\section{Climate and circulation in the Arctic and North Atlantic}

The western Arctic experiences moderately warmer surface air temperatures in winter (about $2^{\circ} \mathrm{C}$ for the PDBR case and $1^{\circ} \mathrm{C}$ for the ULBR case) compared with the control climate (Fig. 8). Over Scandinavia, the Barents Sea, Baffin Bay, and the Irminger Basin (southeast of Greenland) there are temperature reductions of a similar magnitude. The Arctic warming is concentrated in the lower troposphere; at $700 \mathrm{hPa}$, there are small temperature rises downwind of Greenland (Fig. 9). These differences are generally consistent with the changes in low-level tropospheric circulation discussed in the previous section, locally enhanced in some places by changes in sea ice concentration.

Atmospheric heat convergence on Greenland is greatly reduced in summer due to the larger SW absorption as compared to the control climate (Fig. 9). The lowlying central region, as a result of surface heating, even acts as a net heat source for the atmosphere. The removal of the high cold ice sheet surface results in a warmer air column above Greenland, while there is little temperature change in the surrounding region (Fig. 9). In the annual average Greenland imports less heat in the no-ice-sheet runs than in the control. This is consistent with reduced atmospheric subsidence as seen also from the cyclonic change in the low-level circulation. In winter, however, air masses over Greenland seem to benefit from a slightly increased heat import, which is related to the increased autumn and winter cooling of the Greenland surface as compared to the control.

Changes in atmospheric circulation are generally restricted to the area near Greenland, but the North Atlantic circulation is affected by a sea level pressure difference pattern with respect to the control (Fig. 10) that has a relative high over the Greenland and Barents Seas and a relative low over the North Atlantic. The storm track is shifted eastward, with less penetration into the Norwegian Sea. This is consistent with the reduced high pressure system over Greenland and reduced cyclogenesis off Greenland's east coast, and results in a cooler
Barents Sea and increased atmospheric heat convergence over it.

In the ocean, the IFG models have a northeastward shift of the North Atlantic subpolar gyre that is parallel to the changes in the atmospheric circulation, with reduced surface heat transport into the Irminger Basin and Davis Strait. The lower temperature in the Irminger Basin is also evident in SST and is related to a reduction in ocean heat convergence associated to the wind-driven ocean circulation.

There is no evidence of a significant change in the strength of the Atlantic meridional overturning circulation. This is consistent with the limited area affected by substantial changes in the circulation and the unchanged freshwater budget for the North Atlantic (snow accumulation was balanced by the iceberg meltwater flux in the control; it returns to the ocean as runoff in the IFG runs). The removal of the Greenland ice sheet does not have a noticeable climate influence farther afield.

\section{Conclusions}

We have performed a numerical experiment based on the HadCM3 AOGCM in which Greenland has a topography and surface characteristics such as would result from removing the ice sheet. Two cases are considered, one in which the present-day bedrock topography is used and a second in which allowance is made for an isostatic rebound of the earth's crust. All other aspects of model initialization, including the land-sea mask and atmospheric composition, are appropriate for 1860 (the state used as the HadCM3 control climate).

With the exception of one model grid box in the isostatic case, snow does not accumulate over Greenland in the modified climate model, suggesting that a deglaciation of Greenland would be irreversible for Holocene climatic conditions. This is of practical importance because more than one study has indicated that unmitigated anthropogenic climate change is likely to bring about the removal of the ice sheet over coming centuries or millennia. Without the ice sheet, a considerable part of the island is snow free in summer. Isostatic rebound could favor reglaciation, but makes no qualitative different to our results.

There is increased precipitation over Greenland overall, especially on higher ground, and a shift of the precipitation pattern. More precipitation in both solid and liquid form falls over eastern and northern Greenland, and less precipitation, especially solid, in the south. Model performance on the southern coastal range of Greenland, however, suffers from insufficient resolution and thus our results for that region are not robust.

The lack of snow accumulation in spite of increased precipitation compared to the control climate is due to a vigorous early summer melting that is attributable to the warmer overlying atmosphere limiting thermal radiative losses from the surface in spring. Melting of the 

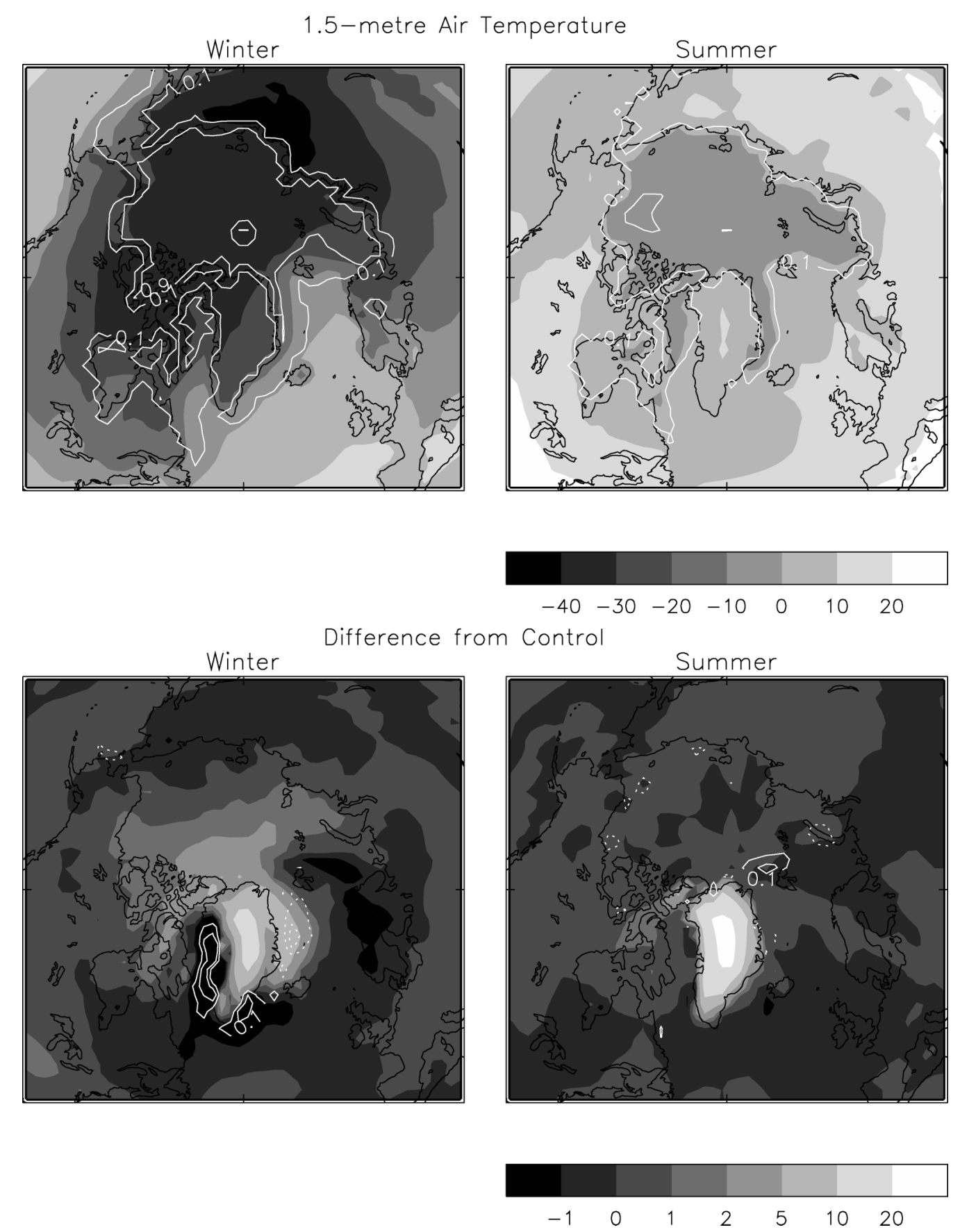

Fig. 8. (top) 1.5-m air winter and summer seasonal mean temperatures (color coding, in ${ }^{\circ} \mathrm{C}$ ) and sea ice concentration (contour lines, dotted for negative values) for the Arctic in the PDBR IFG run. (bottom) Differences with respect to the control.

snow greatly reduces the surface albedo over Greenland, initiating a feedback between solar radiative heating and snow melt, and leading to summer monthly average surface air temperature as high as $15^{\circ} \mathrm{C}$. Summer precipitation falls mostly as rain. The development of a vegetation cover on Greenland would imply even higher summer temperatures. Winter in Greenland without the ice sheet is several degrees warmer than in the control climate, but still quite bitter. Overall, the modified Greenland climate is not very different from that of some forested areas such as in eastern Siberia. Our findings for mass balance and Greenland climate confirm the conclusions of Crowley and Baum (1995), who undertook a similar study with a lower-resolution atmospheric model and prescribed present-day sea surface conditions. 

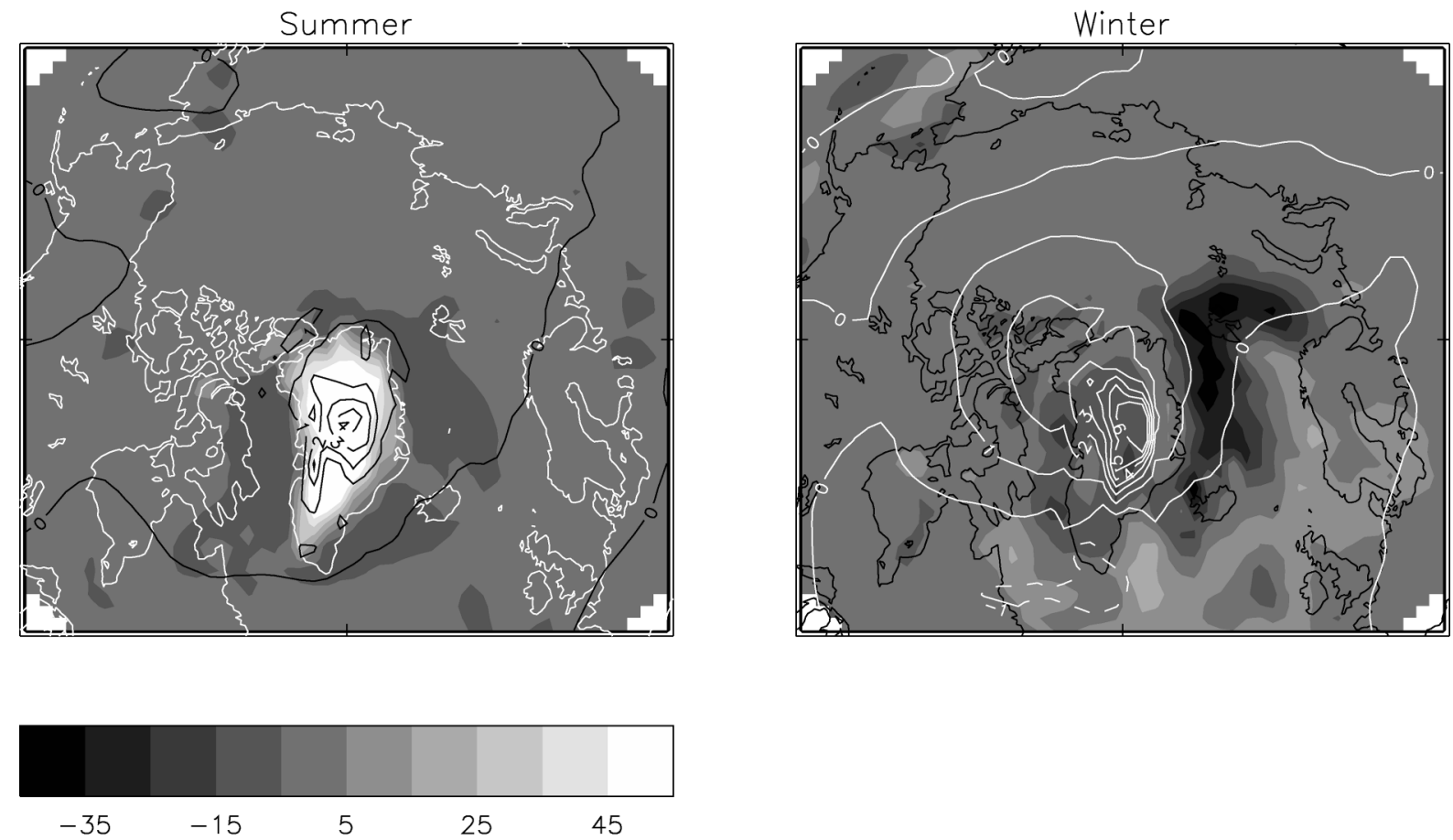

FIG. 9. Differences in atmospheric heat divergence (color coding, in $\mathrm{W} \mathrm{m}^{-2}$ ) and $700-\mathrm{hPa}$ air temperature (contour lines, in $\mathrm{K}$ ) in the Arctic region for the PDBR IFG run with respect to the control run.

The regional atmospheric circulation is substantially different (mean flow cyclonic rather than anticyclonic) when no ice sheet is present, mainly as a result of reduced orographic blocking, especially in winter when there are extensive surface and lower-tropospheric temperature differences of the order of $+1^{\circ} \mathrm{C}$ over the western Arctic. However, changes in summer circulation are local to Greenland, and thus little difference in Arctic and North Atlantic summer climate results from removing the ice sheet.

We conclude that regional snow accumulation is prevented by virtue of the reduced orographic blocking, the lower altitude of the ground and by the onset of the shortwave absorption feedback where thawing occurs. This conclusion does not depend crucially on local details of the atmospheric circulation. However, it does
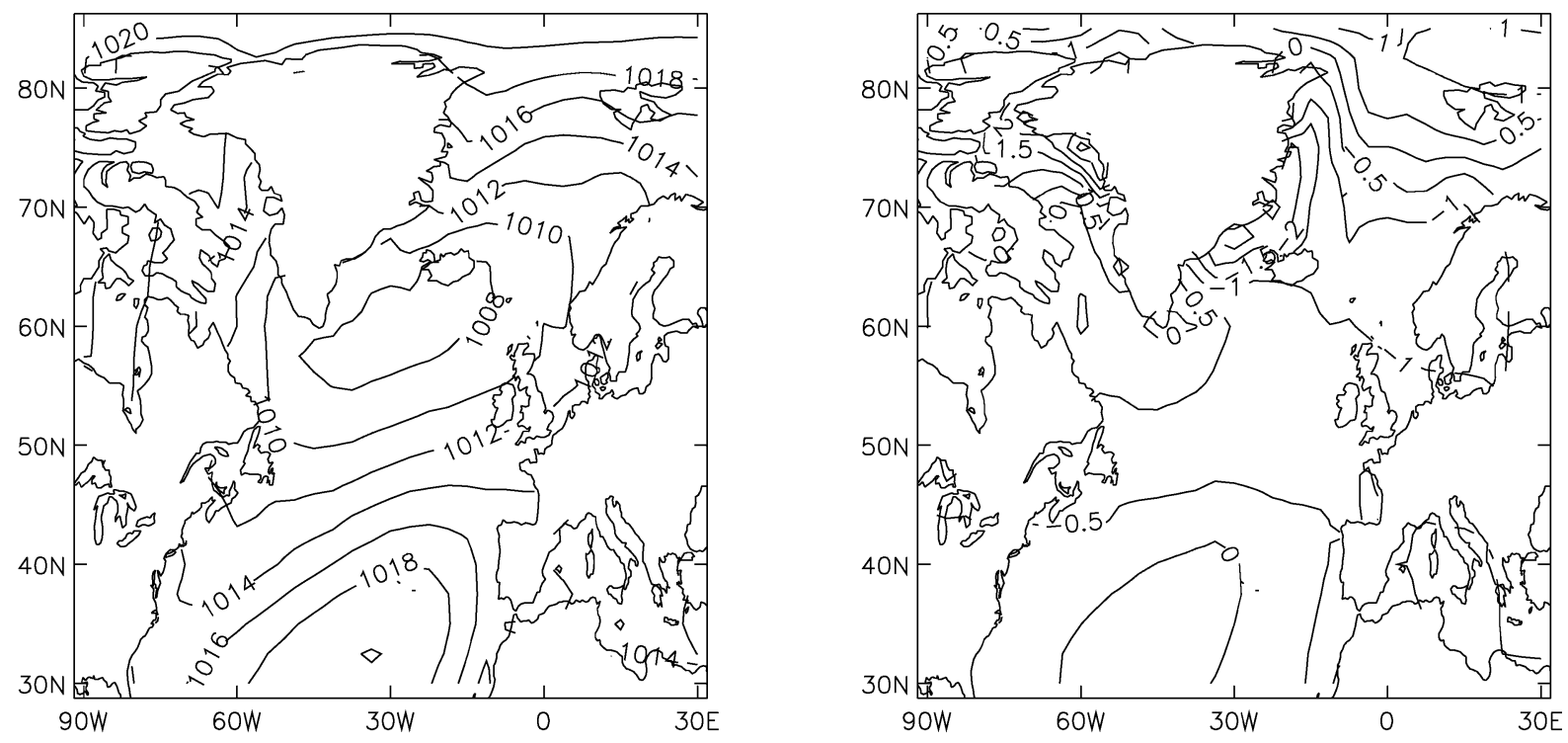

FIG. 10. Winter surface pressure (contour lines, in hPa) for (left) the no-ice-sheet PDBR case and (right) difference from control. 
depend on the sensitivity of the GCM to orography and on the assumed heat transport across the stably stratified boundary layer over Greenland in winter and in spring. Although the performance of the atmospheric model (HadAM3) over Greenland is overall statisfactory (see Murphy et al. 2001), it is very difficult to estimate the uncertainty in the results presented here without complementing them with computations using higher atmospheric resolution and possibly different parameterizations.

A remaining question is whether after removal of the ice sheet the high ground in the southeast could support an ice cap, which might then begin a dynamic regrowth of an ice sheet over more of the Greenland landmass. This question needs to be answered with a dynamic ice sheet model. We therefore plan to undertake an investigation of the possible reinception of the ice sheet using such a model at a higher spatial resolution than that of the AOGCM.

Acknowledgments. We are grateful to Shawn Marshall and Greg Flato for their helpful reviews. This work was supported by the U.K. Department for Environment, Food and Rural Affairs under contract PECD 7/12/37, by the Government Meteorological Research contract, and by the German government through HGF Strategiefonds Projekt 2000/13 SEAL.

\section{REFERENCES}

Church, J. A., J. M. Gregory, P. Huybrechts, M. Kuhn, K. Lambeck, M. T. Nhuan, D. Qin, and P. L. Woodworth, 2001: Changes in sea level. Climate Change 2001: The Scientific Basis, J. T. Houghton et al., Eds., Cambridge University Press, 639-693.

Crowley, T. J., and S. K. Baum, 1995: Is the Greenland ice sheet bistable? Paleoceanography, 10, 357-363.

Cuffey, K. M., and G. D. Clow, 1997: Temperature, accumulation and ice sheet elevation in central Greenland through the last deglacial transition. J. Geophys. Res., 102, 26 383-26 396.

__ , and S. J. Marshall, 2000: Substantial contribution to sea-level rise during the last interglacial from the Greenland ice sheet. Nature, 404, 591-594.

Dahl-Jensen, J., S. J. Johnsen, C. U. Hammer, H. B. Clausen, and J. Jouzel, 1993: Past accumulation rates derived from observed annual layers in the GRIP ice core from Summit, Central Greenland. Ice in the Climate System, W. Peltier, Ed., NATO ASI Series I, Vol. 12, Springer-Verlag, 517-532.

Gibson, J. K., A. Hernandes, P. Kållberg, A. Nomura, E. Serrano, and S. Uppala, 1996: Current status of the ECMWF re-analysis project. Preprints, Seventh Symp. on Global Change Studies, Atlanta, GA, Amer. Meteor. Soc., 112-115.

Gordon, C., C. Cooper, C. A. Senior, H. Banks, J. M. Gregory, T. C. Johns, J. F. B. Mitchell, and R. A. Wood, 2000: The simulation of SST, sea ice extents and ocean heat transports in a version of the Hadley Centre coupled model without flux adjustments. Climate Dyn., 16, 147-168.

Gregory, J. M., and J. A. Lowe, 2000: Predictions of global and regional sea-level rise using AOGCMs with and without flux adjustment. Geophys. Res. Lett., 27, 3069-3072.

Greve, R., 2000: On the response of the Greenland ice sheet to greenhouse climate change. Climate Change, 46, 283-289.

Huybrechts, P., and J. De Wolde, 1999: The dynamic response of the Greenland and Antarctic ice sheets to multiple-century climatic warming. J. Climate, 12, 2169-2188.

Letréguilly, A., P. Huybrechts, and N. Reeh, 1991: Steady-state characteristics of the Greenland ice sheet under different climates. J. Glaciol., 37, 149-157.

Murphy, B. F., I. Marsiat, and P. Valdes, 2002: Atmospheric contributions to the surface mass balance of Greenland in the HadAM3 atmospheric model. J. Geophys. Res., 107, 4556, doi:10.1029/ 2001JD000389.

Ohmura, A., and N. Reeh, 1991: New precipitation and accumulation maps for Greenland. J. Glaciol., 37, 140-148.

—_, M. Wild, and L. Bengtsson, 1996: A possible change in the mass balance of Greenland and Antarctic ice sheets in the coming century. J. Climate, 9, 2124-2135.

Pope, V. D., M. L. Gallani, P. R. Rowntree, and R. A. Stratton, 2000: The impact of new physical parameterizations in the Hadley Centre climate model-HadAM3. Climate Dyn., 16, 123-146.

Thompson, S. L., and D. Pollard, 1997: Greenland and Antarctic mass balances for present and doubled atmospheric $\mathrm{CO}_{2}$ from the GENESIS version-2 global climate model. J. Climate, 10, 871899. 